\title{
Non-woven flax fibre reinforced acrylic based polyester composites: The effect of sodium silicate on mechanical, flammability and acoustic properties
}

\author{
M. F. Ahmad Rasyid ${ }^{1}$, M. S. Salim ${ }^{1}$, H. M. Akil ${ }^{1}$, J. Karger-Kocsis ${ }^{2}$, Z. A. Mohd. Ishak ${ }^{1,3^{*}}$ \\ ${ }^{1}$ School of Materials and Mineral Resources Engineering, Engineering Campus, Universiti Sains Malaysia, \\ 14300 Nibong Tebal, Pulau Pinang, Malaysia. \\ ${ }^{2}$ Department of Polymer Engineering, Faculty of Mechanical Engineering, Budapest University of Technology and \\ Economics, Muegyetem rkp. 3., H-1111 Budapest, Hungary \\ ${ }^{3}$ Cluster for Polymer Composites, Science and Engineering Research Center, Engineering Campus, Universiti Sains \\ Malaysia, 14300 Nibong Tebal, Pulau Pinang, Malaysia.
}

\begin{abstract}
Non-woven flax fibre reinforced acrylic-based polyester (NFA) composites were prepared using an impregnation process. A mixture of acrylic-based polyester $\left(\right.$ Acrodur $\left.^{\circledR}\right)$ with varying sodium silicate (SS) loadings was applied to impregnate the non-woven flax fibre mat. Flexural tests were performed to evaluate the mechanical properties of the composites. Flammability properties were assessed via UL94 test and limiting oxygen index (LOI). The mechanical properties of NFA composites decreased substantially with increment in SS loading. The addition of SS resulted in significant improvement of flame retardancy, whereby UL94 rating enhanced from V-1 to V-0, while the LOI values increased from 24 to 40 . Sound absorption coefficients of the NFA composites were measured via two-microphone transfer function technique in impedance tube. The sound absorption properties of NFA composites also improved with the incorporation of SS, whereby the sound absorption coefficient increased up to 0.87 at $2000 \mathrm{~Hz}$ frequency. Based on the overall evaluation, $20 \mathrm{wt} \%$ of SS effectively increased flame retardancy and sound absorption properties, along with moderate deterioration in flexural properties. The scanning electron microscopic (SEM) analysis of the composites surfaces displayed formation of voids and irregular structures at higher SS loading, which reduced the mechanical properties of NFA composites. The SEM images offered supportive evidences on the role of hollow lumen structures in natural fibres to ensure better sound absorption performance in NFA composites.
\end{abstract}

Keywords: polymer composites, thermosetting resins, mechanical properties, non-woven flax fibre mat, acoustic properties

\section{Introduction}

Since the past decade, demand for natural and sustainable products has increased significantly from various manufacturing sectors, particularly in construction, packaging, and automotive, due to the promising potential in benefitting the natural environment and in addressing the public concern over environmental protection and regulation. As such, natural fibres played a key role in developing biocomposites in substituting conventional, synthetic, and non-renewable reinforcing materials, such as fibre glass and aramid fibre. Replacement of these conventional reinforcing materials with natural fibres offers various advantages, such as low density, high specific strength, good sound absorption properties, and biodegradability [1-3]. Natural fibre composites have been utilised by the European car-makers for dash boards, door panels, headliners, seatbacks, and

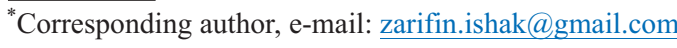
(C) BME-PT 
package trays. The global car sales have been estimated to hit 115 million units by year 2024, which suggests substantial increment in the demand of natural fibre composites within the automotive industries.

Flax (Linum usitatissimum) is a widely used natural fibre in biocomposites in recent years. Akampumuza et al. [4] reported that, flax fibre is among the highest natural fibre consumption which contribute to $19 \%$ of the total tonnage. Flax fibre contains cellulose (64-75\%), hemicellulose (16-21\%), lignin (2-3\%), and pectin (2-3\%) [5]. Due to the high cellulose content, flax is among the strongest and stiffest natural fibres. Cellulose is a semi-crystalline polysaccharide with a large amount of hydroxyl groups that reflects hydrophilic nature and incompatibility with hydrophobic polymer matrix, resulting in poor adhesion [6-9]. Hence, chemical or physical modification is required to enhance the fibre-matrix adhesion for both thermoplastic and thermoset compounds. Several chemical methods, such as alkali treatment, acetylation, permanganate, isocyanate treatment, acrylation, maleated, and silane coupling agents, have been investigated by many researchers [10-13]. Nevertheless, high flammability is the main drawback that limits the application of flax fibre and other natural fibres in many fields [3, 14-16]. Natural fibres are commonly fabricated using hand lay-up, compression moulding, pultrusion, resin transfer moulding and resin impregnation. Moreover, there is a new fabrication technique have been developed such as infiltration and deposition of layer by layer (LbL) of polymers which has been described elsewhere $[17,18]$. This techniques is eco-friendly due to the used of starch and water as a binder and solution. However, the limitation of this technique is slow manufacturing process which is not suitable for mass production. Meanwhile, the advantages of the impregnation technique used in this work includes fast and continuous manufacturing process but require a large amount of resin.

Vinyl ester and polyester are among the conventional thermoset matrices commonly used for natural composites. Nonetheless, vinyl ester and polyester matrices emit styrene during their processing and in their finished product, which is harmful to humans [19]. Other thermoset resins, such as resole-type phenolic resins (phenol-formaldehyde), emit formaldehyde and cause respiratory, eye, and nose irritation. Although a substantial number of studies have used flax fibre as reinforcement in various conventional resins, none has reported on first, the properties of flax-reinforced acrylic-based polyester composites prepared via impregnation process and second, the use of SS as a flame-retardant additive. Acrodur ${ }^{\circledR}$ refers to a trade name of a new generation of acrylic-based polyester resin initiated by Badische Anilin und Soda Fabrik (BASF) company. Unlike most thermosets, these polymers neither contain volatile-organic compound (VOC) and formaldehyde nor emit toxic during the cross-linking, thus safe for human and environment. The only by-product is water, hence suitable for the present green technologies. Additionally, Acrodur ${ }^{\mathbb{R}}$ exhibits excellent storage stability and high heat resistance.

High flammability is a primary drawback that limits the application of natural fibres in many fields, including the automotive industry. In the past, the typical flame-retardants for polyester resin were phosphorous materials, alumina trihydrate, ammonium salts, zinc borate/boric acid, and halogenated additives [20-24]. The halogenated additives, such as bromine or chlorine-based, were widely applied due to their better flame retardancy. Nevertheless, halogenated composites generate toxic and corrosive smoke during fire, which lead to fortification. Alternatively, sodium silicate (SS) is often referred to as water glass, which is an exceptional candidate as a flameretardant. SS belongs to the family of soluble silicates that represent one of the most versatile inorganic chemicals available. SS is manufactured by fusing high-purity quartz sand $\left(\mathrm{SiO}_{2}\right)$ with sodium or potassium carbonate $\left(\mathrm{Na}_{2} \mathrm{CO}_{3}\right.$ or $\left.\mathrm{K}_{2} \mathrm{CO}_{3}\right)$ in an open hearth furnace at $1100-1200^{\circ} \mathrm{C}$. Next, the resulting glass is dissolved by using high pressure steam to generate clear and slightly viscous liquid silicate or 'waterglass'. SS is commonly used for fireproofing paper, wood, and cement. Sahoo et al. [25] reported that the addition of SS in poly (butylacrylate) (PBA) nanocomposites resulted in better flame-retardant property and thermal stability, when compared to raw PBA by using cone calorimeter and thermogravimetric analysis. SS/polyisocyanate organic-inorganic hybrid material was synthesised by Cheng et al. [26]. The cone calorimetric and LOI test revealed that the hybrid material displayed better flame-retardant properties with an obvious decrease in heat release rate, spread rate of fire and decomposition rate, while increment in limiting oxygen index (LOI) value. Medina and Schledjewski [27] reported 
on the effectiveness of SS in improving flame retardancy properties of natural fibre reinforced thermoset composites. The presence of SS on the surface of kenaf/hemp (70:30) mat, as evidenced by EDX, was believed to be responsible for the self-extinguishing behaviour in the composites.

Automotive manufacturers emphasise the use of efficient sound-absorptive materials in vehicles to reduce unwanted noise. Natural fibres and in combination with other synthetic fibres, such as PP and PET in the form of non-woven needle-punched mats, have been proven to be effective noise-absorbing materials when placed between a sound source (tyres, vibrating parts) and receiver (vehicle passengers side), mainly because they absorb unwanted sound by dissipating sound wave energy. To date, a large variety of carpet-type non-woven materials are used in floor coverings, luggage areas, and rear shelves in passenger cars. However, studies on sound absorption properties of moulded non-woven natural fibre composite materials are in scarcity.

This study assessed the effect of SS on mechanical, flammability, and acoustic properties of non-woven flax fibre reinforced acrylic-based (NFA) polyester; Acrodur $^{\circledR}$ (NFA) composites. Fourier transform-infrared spectroscopy (FTIR) and scanning electron microscopy (SEM) were applied to analyse chemical and physical modifications of flax composite, while the mechanical properties were examined via flexural test. The flammability properties were evaluated by using UL94 and LOI tests. Sound absorption coefficients of the NFA composites were measured via two-microphone transfer function technique in impedance tube. Focus was given in low- and mid-frequencies ranging between 0 and close to $2000 \mathrm{~Hz}$. Lalor and Priebsch [28] reported that the maximum interior noise of passenger cars moving at $100 \mathrm{~km} / \mathrm{h}$ speed was at frequency below $1000 \mathrm{~Hz}$. Noise in this frequency range is predominantly linked with structureborne i.e. noise generated by acoustic radiation from the vibrating cabin walls that are mechanically excited as frequently experienced in automotive. The structure borne input is related to a combination of tyre/road interaction and engine. Thus, this work produced sustainable and eco-friendly composite materials with a good combination of mechanical, flammability, and acoustic properties that suggest several suitable applications, such as interior components in automotive.

\section{Experimental section}

\subsection{Materials and sample preparation}

\subsubsection{Materials}

Non-woven flax fibre (NWFF) mat with an areal density of $1300 \mathrm{~g} / \mathrm{m}^{2}$ was supplied by EcoTechnilin Ltd, France. Sodium silicates (SS) containing $26 \mathrm{wt} \%$ $\mathrm{SiO}_{2}$ and $10.6 \mathrm{wt} \% \mathrm{Na}_{2} \mathrm{O}$ was supplied by SigmaAldrich (M) Pvt. Ltd., Malaysia with a density of $1.39 \mathrm{~g} / \mathrm{ml}$. Acrodur ${ }^{\circledR} 950 \mathrm{~L}$ resin was provided by BASF. Table 1 presents both chemical and physical properties of Acrodur $^{\circledR} 950 \mathrm{~L}$. The resin matrix is an aqueous solution of a modified poly(carboxylic acid) with poly(hydric alcohol) as a crosslinking agent that creates a durable polyester thermoset material. Initially, it is in thermoplastic form, and then, it crosslinks at a temperature beyond $130^{\circ} \mathrm{C}$.

\subsubsection{Fabrication of composites}

NFA composites with a maximum of $70 \mathrm{wt} \%$ of fiber were fabricated using resin impregnation process. Accordingly, NWFF was first dried at $60^{\circ} \mathrm{C}$ for $3 \mathrm{~h}$ in an air-circulating oven. Next, Acrodur $950 \mathrm{~L}$ resin was mixed with different SS loadings for 5 minute (see Table 2). The mixture was subsequently poured into resin bath. The impregnation process was performed by introducing the NWFF mat to the resin bath of impregnation machine. Then, the impregnated mats were post-dried in an oven at $70^{\circ} \mathrm{C}$ until the moisture content in prepreg was approximately $15 \%$. The impregnated mats were moulded in a GOTECH compression moulding machine (model GT7014-H, Taiwan) at $200^{\circ} \mathrm{C}$ for $4.6 \mathrm{~min}$ at 14 bar.

Table 1. Chemical and physical properties of Acrodur ${ }^{\circledR}$ 950LF.

\begin{tabular}{|l|c|}
\hline \multicolumn{1}{|c|}{ Property } & Typical value \\
\hline Density & $1.20 \mathrm{~g} / \mathrm{cm}^{3}$ \\
\hline Viscosity range & $900-2500 \mathrm{mPa} \cdot \mathrm{s}$ \\
\hline $\mathrm{pH}$ & $2.5-4.0$ \\
\hline
\end{tabular}

Table 2. Formulation of NFA composites.

\begin{tabular}{|c|c|c|c|}
\hline Material & $\begin{array}{c}\text { Acrodur }^{\circledR} \text { resin } \\
{[\%]}\end{array}$ & $\begin{array}{c}\text { Sodium silicate } \\
{[\%]}\end{array}$ & Denotation \\
\hline 1 & 100 & 0 & SS0 \\
\hline 2 & 90 & 10 & SS10 \\
\hline 3 & 80 & 20 & SS20 \\
\hline 4 & 70 & 30 & SS30 \\
\hline
\end{tabular}




\subsubsection{Viscosity test}

The viscosity of the Acrodur ${ }^{\circledR}$ resin with varied SS loading [wt $\%$ ] was measured using a digital viscometer DV-II PRO (Brookfield, Massachusetts, USA) with RV spindles. The viscosity measurement was performed on 5 specimens and the changes in viscosity as a function of time was measured for 600 s at room temperature. The optimum SS loading on viscosity increment was determined.

\subsubsection{Fourier transform infrared (FTIR) analysis}

The FTIR analysis was conducted to investigate the impact of SS on the changes in chemical structure of the material using a spectroscopy Spectrum One (Perkin-Elmer, Wellesley, MA, USA). The spectra were measured in a spectral range of $4000-400 \mathrm{~cm}^{-1}$ with 32 scans taken for each sample at $2 \mathrm{~cm}^{-1}$ resolution. The samples were dried and ground to fine powder and mixed with potassium bromide $(\mathrm{KBr})$. This mixture was compressed into pellets and analysed using Perkin Elmer FTIR Spectrometer.

\subsubsection{Differential scanning calorimetry (DSC)}

DSC analysis using Perkin-Elmer model Pyris Diamond DSC-6 analyser was used to estimate the degree of the crosslinking of the composites. Approximately $20 \mathrm{mg}$ of composite samples was then enclosed in aluminium pan and scanning was conducted at a heating rate of $10{ }^{\circ} \mathrm{C} / \mathrm{min}$ in nitrogen gas environment. DSC data was used to detect the enthalpy of residual crosslinking capability ( $\left.\Delta H_{\text {Residual }}\right)$ in the composites samples and infer the degree of crosslinking by comparing it to the enthalpy of crosslinking reaction $\left(\Delta H_{\text {Resin }}\right)$ of an uncured Acrodur ${ }^{\circledR}$ resin. The degree of crosslinking was then calculated by using Equation (1) [29]:

Degree of crosslinking $[\%]=\frac{\Delta H_{\text {Resin }}-\Delta H_{\text {Residual }}}{\Delta H_{\text {Resin }}}$

The degree of crosslinking was calculated using $\Delta H_{\text {Resin }}$ of $140 \mathrm{~J} / \mathrm{g}$ for the Acrodur

\subsubsection{Thermogravimetric analysis (TGA)}

Thermogravimetric analysis (TGA) was performed to determine the thermal stability of composites samples against temperature. The analysis was carried out using a Perkin Elmer Pyris Diamond TGA analyser at a heating rate of $10^{\circ} \mathrm{C} /$ minute at the temperature range of room temperature to $600{ }^{\circ} \mathrm{C}$. under inert atmosphere of nitrogen gas.

\subsubsection{Measurement of composite density and void content}

The experimental density of the composite was determined with density balance XT 220A (Precissa, Dietikon, Switzerland) by adhering to ASTM D792 (test method A) with methanol (Sigma, ACS reagent) as a liquid medium. For all the studied composites, 6 samples were taken at varied locations within the composites samples and the average values of density were recorded. The void content of the composite was calculated by using Equation (2):

$V_{\mathrm{v}}=1-\rho_{\mathrm{c}}\left(\frac{W_{\mathrm{f}}}{\rho_{\mathrm{f}}}+\frac{W_{\mathrm{m}}}{\rho_{\mathrm{m}}}\right)$

where $V_{\mathrm{v}}$ is the volume fraction of voids, $\rho \mathrm{c}$ refers to the density of composite, $W_{\mathrm{f}}$ denotes the weight percent of fibre [\%], $W_{\mathrm{m}}$ represents the weight percent of matrix [\%], $\rho_{\mathrm{f}}$ is defined as the density of fibre $\left[\mathrm{g} / \mathrm{cm}^{3}\right]$, and $\rho_{\mathrm{m}}$ is the density of matrix $\left[\mathrm{g} / \mathrm{cm}^{3}\right]$.

\subsubsection{Flexural test}

Both flexural strength and modulus of NFA were determined by using a three-point bending test method, as recommended in the ASTM D790 standard using Universal Testing Machine Instron 3366 (Instron, Massachusetts, USA). The testing was conducted at a crosshead speed of $3 \mathrm{~mm} / \mathrm{min}$ and a span to depth ratio of 16:1. The average values of flexural strength and modulus were taken from a total of 5 composite samples.

\subsubsection{Flammability test}

The limiting oxygen index (LOI) test was carried out by adhering to ASTM D 2863 using FTT0080 Oxygen Index apparatus (Fire Testing Technology Ltd., East Grinstead, UK). Specimens of $120 \mathrm{~mm} \times 6.5 \mathrm{~mm} \times$ $4 \mathrm{~mm}$ in size were clamped vertically in a transparent glass chimney. The test was repeated under various concentrations of oxygen and nitrogen in order to determine the minimum concentration of oxygen required in the oxygen/nitrogen mixture to burn the sample in $3 \mathrm{~min}$. The UL-94V vertical burning test was performed using a Plastics HVUL horizontal vertical flame chamber (Atlas Fire Science Products, Chicago, USA). The specimen dimensions were $125 \mathrm{~mm} \times 13 \mathrm{~mm} \times 3 \mathrm{~mm}(\ell \times w \times t)$. A flame of $20 \mathrm{~mm}$ in height was used to light one end of the sample, 
while maintaining the distance between the end of the sample and the burner flame at $10 \mathrm{~mm}$. All test bars underwent two trials; each trial consisted of ignition for $10 \mathrm{~s}$. After $10 \mathrm{~s}$, the flame was removed and the ignition time was recorded.

\section{Results and discussion}

\subsection{Viscosity test}

Figure 1 displays the impact of SS loading on the viscosity of Acrodur resin. For all cases, the viscosity increased at the initial stage and then stabilised at a certain value depending on the SS loading.

Up to $30 \mathrm{wt} \% \mathrm{SS}$, the viscosity attained stability at fairly low values in the range of $4000 \mathrm{~s}$ to $6000 \mathrm{~Pa} \cdot \mathrm{s}$. However, a dramatic increase in viscosity was noted at $40 \mathrm{wt} \% \mathrm{SS}$ until it stabilised at approximately $15000 \mathrm{~Pa} \cdot \mathrm{s}$. Such high viscosity inhibited adequate impregnation of flax fibre mat by Acrodur ${ }^{\circledR}$ resin. Thus, $30 \mathrm{wt} \% \mathrm{SS}$ was considered as the maximum loading to fabricate NFA composites.

\subsection{FTIR analysis}

Figure 2 presents the FTIR spectra of the Acrodur ${ }^{\circledR}$ resin, SS, and NFA composite at varied SS loadings.

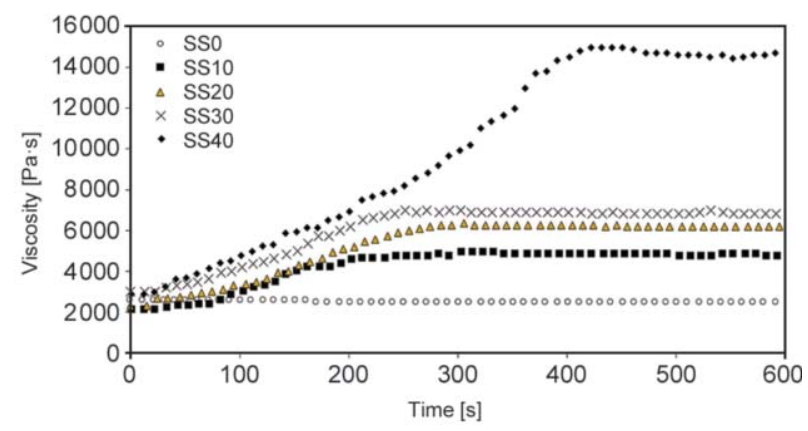

Figure 1. Viscosity of the matrix system mix with sodium silicate.

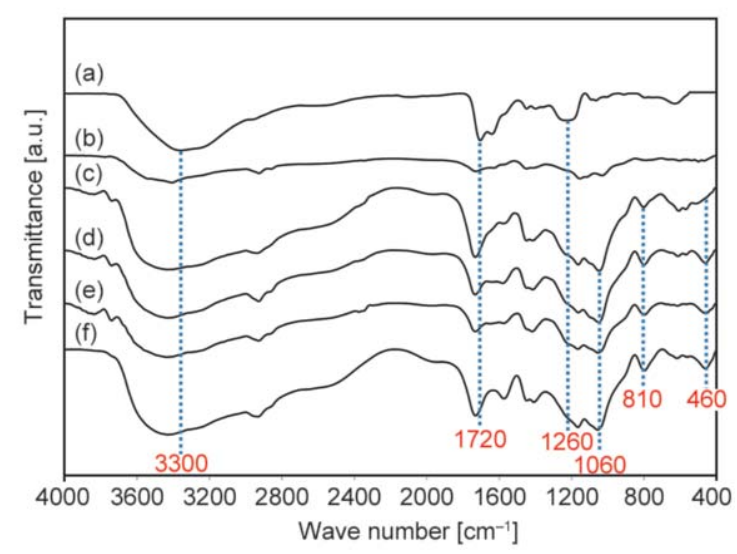

Figure 2. FTIR spectra of tested sample: (a) uncured Acrodur $^{\circledR}$ resin; (b) cured Acrodur ${ }^{\circledR}$ resin; (c) SS0; (d) SS10; (e) SS20; (f) SS30.
In the case of uncured Acrodur ${ }^{\circledR}$ resin, as shown in Figure 2 curve (a), the $\mathrm{O}-\mathrm{H}$ stretch broad peak centred at $3300 \mathrm{~cm}^{-1}$ and $\mathrm{C}-\mathrm{O}$ stretching vibration of alcohols at $1260-1000 \mathrm{~cm}^{-1}$ could be attributed to the presence of polyalcohol. OH stretch in the 3300 $2500 \mathrm{~cm}^{-1}$ region centred near $3000 \mathrm{~cm}^{-1}$ and $\mathrm{C}=\mathrm{O}$ stretch at $1720 \mathrm{~cm}^{-1}$ could be linked to the presence of polycarboxylic.

As for cured Acrodur ${ }^{\circledR}$ resin displayed in Figure 2 curve $b$, reduction of polyalcohol and polycarboxylic contents was observed due to the crosslinking reaction of both compounds to form polyester. There is a decrease in the intensity of the $\mathrm{O}-\mathrm{H}$ stretch broad peak centred at $3300 \mathrm{~cm}^{-1}$ and disappearance of peak $\mathrm{C}-\mathrm{O}$ stretching vibration at $1260 \mathrm{~cm}^{-1}$ corresponding to the reduction of polyalcohol content.

The reduction of polycarboxylic content, however, was justified by the decrease in the intensity of $\mathrm{OH}$ stretch in the $3300-2500 \mathrm{~cm}^{-1}$ region and $\mathrm{C}=\mathrm{O}$ stretch at $1720 \mathrm{~cm}^{-1}$. The presence of polyester could be identified by the appearance of $\mathrm{C}-\mathrm{O}$ stretching vibration peak of ester group at $1160 \mathrm{~cm}^{-1}$, which coexisted with the $\mathrm{C}=\mathrm{O}$ stretching vibration at $1720 \mathrm{~cm}^{-1}$. Figure 2 curve $\mathrm{c}-\mathrm{f}$ illustrates the FTIR spectra of the composites. As for the SS0 composite presented in Figure 2 curve $\mathrm{c}$, the presence of polyalcohol and polycarboxylic was confirmed by the presence of $\mathrm{O}-\mathrm{H}$ stretch broad peak centred at $3300 \mathrm{~cm}^{-1}$ and $\mathrm{C}=\mathrm{O}$ stretch at $1720 \mathrm{~cm}^{-1}$. The incorporation of SS into NFA composites resulted in the formation of additional peaks at 810 and $460 \mathrm{~cm}^{-1}$, which could be attributed to the stretching vibration of Si-O-Si bond and the bending vibration of $\mathrm{Si-}-\mathrm{O}$ bond. The intensity of these peaks increased with SS loading. Additionally, a strong peak was detected at $1060 \mathrm{~cm}^{-1}$, which could be related to the $\mathrm{Si}-\mathrm{O}-\mathrm{Si}$ or $\mathrm{Si}-\mathrm{O}-\mathrm{C}$

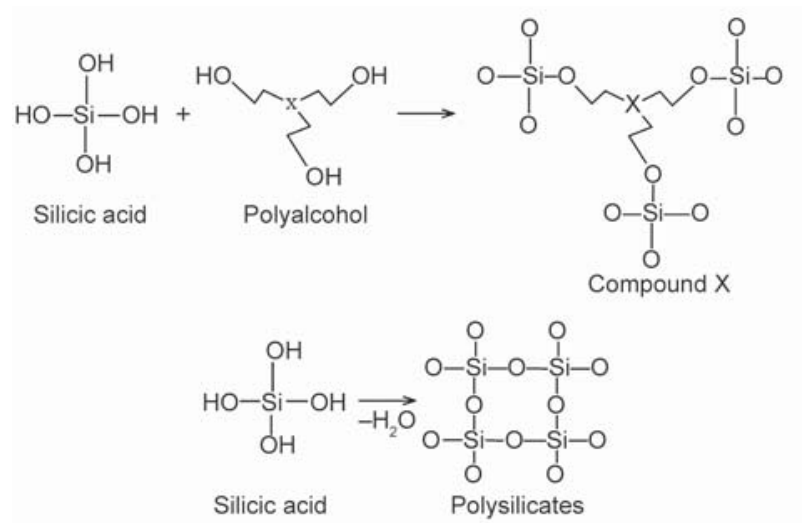

Figure 3. Possible chemical reactions of silicic acid to form compound ' $\mathrm{X}$ ' and polysilicate. 
bond. The introduction of SS in uncured Acrodur ${ }^{\circledR}$ resin (aqueous, containing 50\% water) yielded silicic acid (silanol group) and $\mathrm{NaOH}$ by-products. The presence of silicic acid might have reacted either with polyalcohol or with itself to generate compound ' $\mathrm{X}$ ' or polysilicates, respectively (see Figure 3 ). The preference of polyalcohol to react with silicic acid increased the amount of unreacted polycarboxylic.

\subsection{Thermal properties}

Figure 4 presents the typical DSC thermograms of uncured Acrodur ${ }^{\mathbb{B}}$ resin and cured NFA composites. The peak noted at $100^{\circ} \mathrm{C}$ corresponded to the evaporation of residual moisture within the composite, while the second peak at $200{ }^{\circ} \mathrm{C}$ corresponded to the crosslinking reaction of Acrodur ${ }^{\circledR}$ resin.

The peak recorded in the $190-230^{\circ} \mathrm{C}$ range was linked to heat generated during the crosslinking reaction of Acrodur resin. The effect of SS loading on the degree of crosslinking of the composites is summarised in Table 3. The measured enthalpy of residual crosslinking for uncured Acrodur ${ }^{\circledR}$ resin and SS0 were $\left(\Delta H_{\text {Resin }}=140.00 \mathrm{~J} / \mathrm{g}\right)$ and $\left(\Delta H_{\text {Residual }}=18.73 \mathrm{~J} / \mathrm{g}\right)$, respectively, which corresponded to the degree of crosslinking at $86.62 \%$. The degree of crosslinking was estimated using Equation (1) as mention in Section 2.1.5. The enthalpy of residual crosslinking increased with increment of SS loading. The presence

Table 3. Effect of SS loading on enthalphy of residual crosslinking and degree of crosslinking of NFA composites.

\begin{tabular}{|l|c|c|}
\hline Composites & $\begin{array}{c}\Delta \boldsymbol{H}_{\text {Residual }} \\
{[\mathbf{J} / \mathbf{g}]}\end{array}$ & $\begin{array}{c}\text { Degree of crosslinking } \\
{[\mathbf{\%}]}\end{array}$ \\
\hline SS0 & 18.73 & 86.62 \\
\hline SS10 & 25.86 & 81.53 \\
\hline SS20 & 30.41 & 78.28 \\
\hline SS30 & 36.48 & 73.94 \\
\hline
\end{tabular}

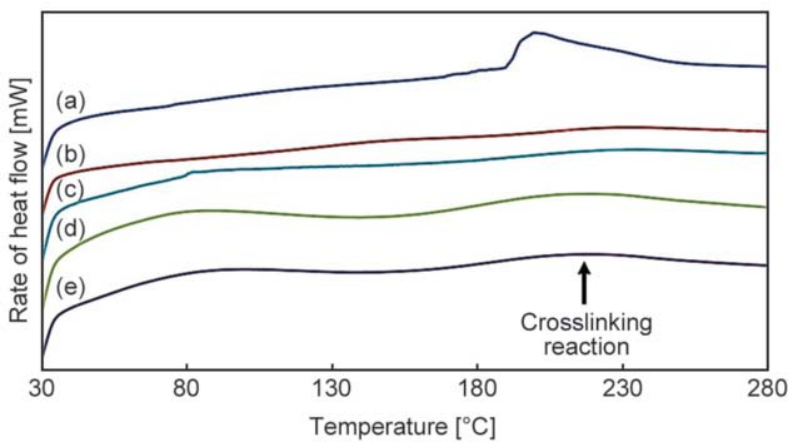

Figure 4. DSC thermograms of Acrodur ${ }^{\circledR}$ resin and NFA composites; composites (a) Uncured Acrodur ${ }^{\circledR}$ resin (b) SS0 (c) SS10 (d) SS20 and (e) SS30.

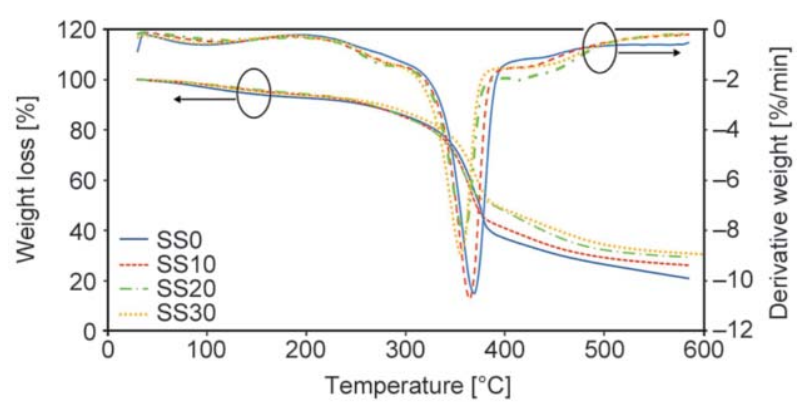

Figure 5. Thermogravimetry (TGA) and differential thermogravimetry (DTG) of NFA composites with different SS loading.

of SS in Acrodur ${ }^{\circledR}$ resin interfered with the crosslinking reaction between polycarboxylic and polyalcohol to form polyester that reduced the degree of crosslinking, as explained earlier in Section 3.2.

Figure 5 shows the TGA and derivative thermogravimetry (DTG) of NFA composites at different SS loading. The degradation temperatures, $T_{10}$ which corresponds to the temperature at which $10 \%$ weight loss occurred are summarized in Table 4.

In general, the DTG curves showed three distinct stages. The first stage of weight loss started from 80 to $100^{\circ} \mathrm{C}$, corresponding to water evaporation. Major degradation that occurred at the second stage in the range of $180-270^{\circ} \mathrm{C}$ was attributable to degradation of lower boiling point polyester components, such as $\mathrm{CO}, \mathrm{CO}_{2}, \mathrm{CH}_{4}$, ethylene, and acetylene [19]. The third stage of weight loss at temperatures ranging from 320 to $380^{\circ} \mathrm{C}$ indicated degradation of crosslinked polyester [30]. Table 4 presents the effect of SS loading on degradation temperature. The degradation temperature, $T_{10}$, for the composite increased with increment in SS loading, which could be related to enhancement in thermal stability of the composites in the presence of SS. Cheng et al. [31] reported that the addition of SS loading to polyisocyanate (monomer of polyurethane besides polyol) imparted significant improvement in thermal stability of polyurethane. Improvement of thermal stability after incorporation of inorganic additives is commonly attributed

Table 4. TGA result of NFA composite.

\begin{tabular}{|l|c|c|}
\hline \multicolumn{1}{|c|}{ Samples } & $\begin{array}{c}\boldsymbol{T}_{\mathbf{1 0}} \\
{\left[{ }^{\circ} \mathbf{C}\right]}\end{array}$ & $\begin{array}{c}\text { Char content } \\
{[\%]}\end{array}$ \\
\hline Neat resin (cured) & 185 & 19.50 \\
\hline SS0 & 259 & 20.93 \\
\hline SS10 & 265 & 26.16 \\
\hline SS20 & 269 & 29.40 \\
\hline SS30 & 271 & 36.46 \\
\hline
\end{tabular}


to the formation of barrier network that prevents the transfer of volatile products and heat during the degradation process [32].

Table 4 showcases that the char content increased with increased SS loading. Increment of char content could be attributed to the presence of ash and thick polysilicate coating deposited on the surface of the composites. This is in agreement with the work performed by Vaia et al. [33], wherein the presence of silicates in PA6/layered-silicates nanocomposites increased carbonaceous char yields. Further evaluation of the char content in detecting the composition of the compound was performed via EDX analysis. Upon absence of SS, the EDX spectra of NFA composite (see Figure 6a) indicated the presence of carbon and oxygen elements. However, with incorporation of SS into NFA composite, the EDX revealed the presence of $\mathrm{Si}$ and $\mathrm{Na}$ elements, along with increased intensities for both elements with increment in SS loading (see Figure 6b-6d).

\subsection{Mechanical and morphological properties} Table 5 presents the impact of SS loading on flexural strength and modulus of NFA composites. The addition of SS up to $20 \mathrm{wt} \%$ displayed nil impact on both
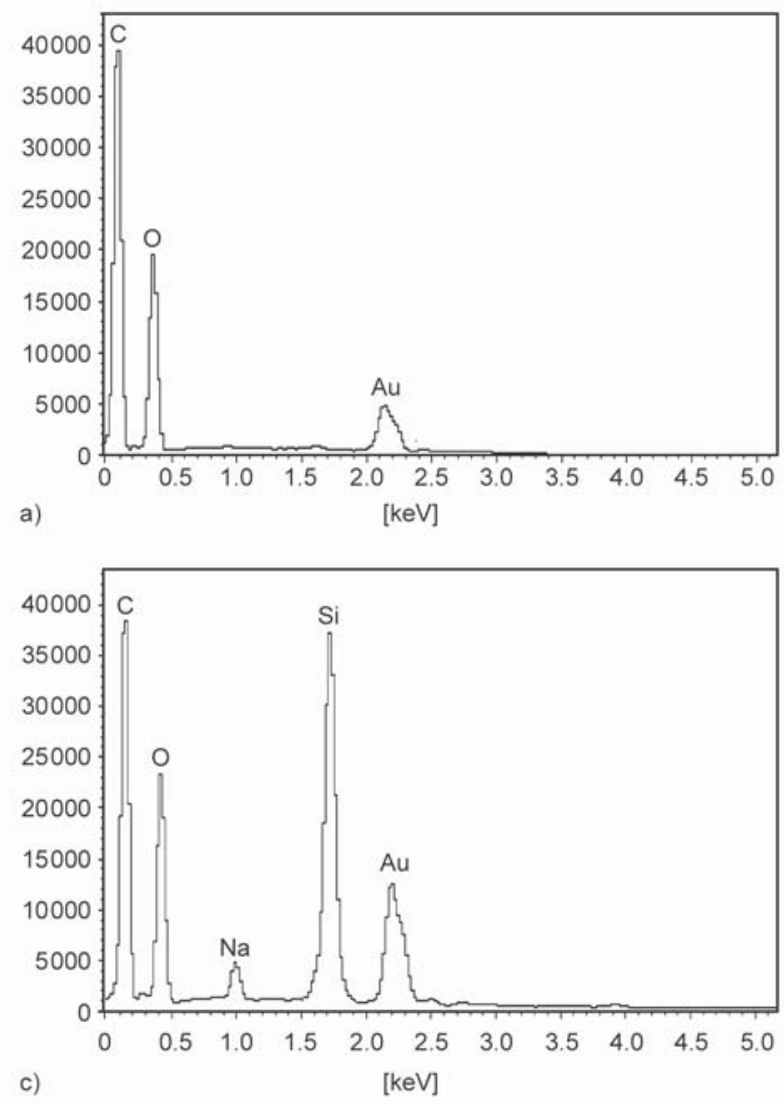

flexural strength and modulus. However, slight drop of 17 and $11 \%$ in flexural strength and modulus, respectively, has been observed after adding $30 \mathrm{wt} \%$ SS. This reduction was attributable to two main possibilities. First, the presence of high loading of SS could interfere with the crosslinking reaction between polycarboxylic and polyalcohol, thus resulting in less conversion of the resin into rigid thermosetting polyester (see Table 3). Second, the presence of high void content up to $33 \%$ (see Table 5) may have deteriorated the flexural properties of the composite. The specific properties of NFA remained fairly unchanged with incorporation of up to $20 \mathrm{wt} \% \mathrm{SS}$. Further addition of SS resulted in a more dramatic drop in specific properties. Islam et al. [19] also reported high void content of up to $35.3 \%$ for flax fabric

Table 5. Effect of SS loading on densities and void content of NFA composites.

\begin{tabular}{|l|c|c|c|c|}
\hline Samples & $\begin{array}{c}\text { Density } \\
{\left[\mathbf{k g} / \mathbf{m}^{\mathbf{3}}\right]}\end{array}$ & $\begin{array}{c}\text { Void } \\
\text { contents } \\
{[\mathbf{\%}]}\end{array}$ & $\begin{array}{c}\text { Flexural } \\
\text { strength } \\
{[\mathbf{M P a}]}\end{array}$ & $\begin{array}{c}\text { Flexural } \\
\text { modulus } \\
{[\mathbf{G P a}]}\end{array}$ \\
\hline SS0 & 1160 & 13 & $86.9 \pm 3.4$ & $7.2 \pm 0.2$ \\
\hline SS10 & 1100 & 17 & $89.5 \pm 2.1$ & $7.4 \pm 0.3$ \\
\hline SS20 & 1060 & 20 & $86.1 \pm 3.5$ & $7.1 \pm 0.1$ \\
\hline SS30 & 870 & 33 & $72.2 \pm 4.3$ & $6.4 \pm 0.3$ \\
\hline
\end{tabular}
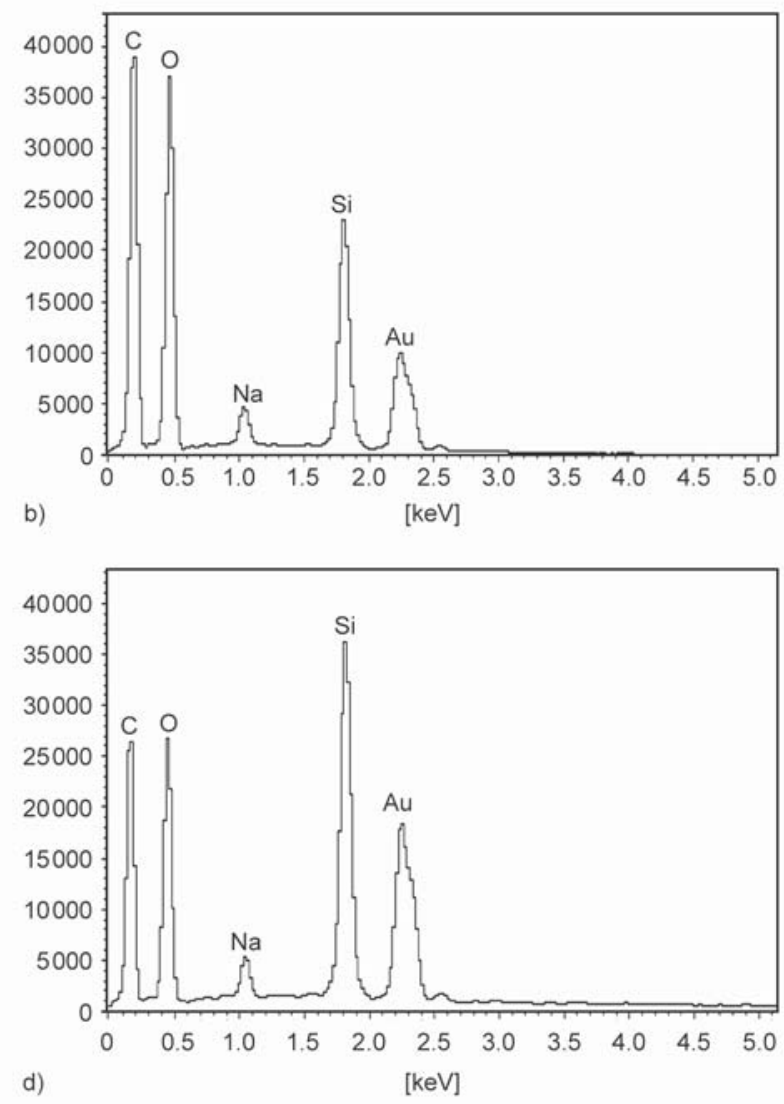

Figure 6. EDX spectra of NFA composite: (a) SS0, (b) SS10, (c) SS20, (d) SS30. 


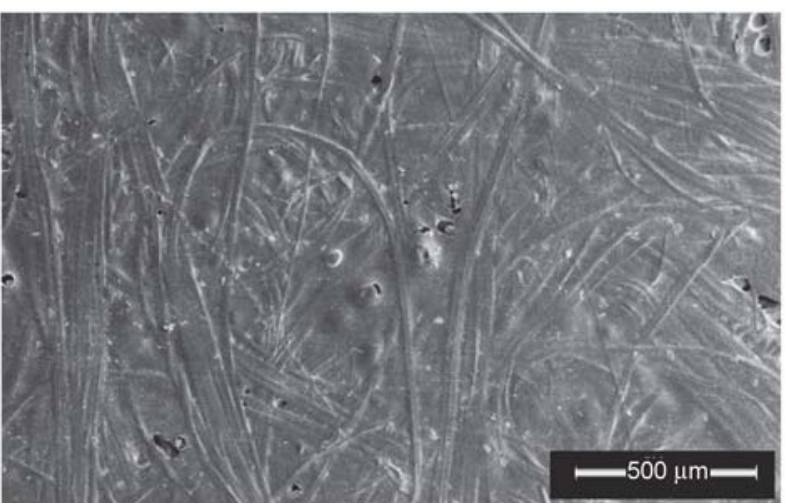

a)

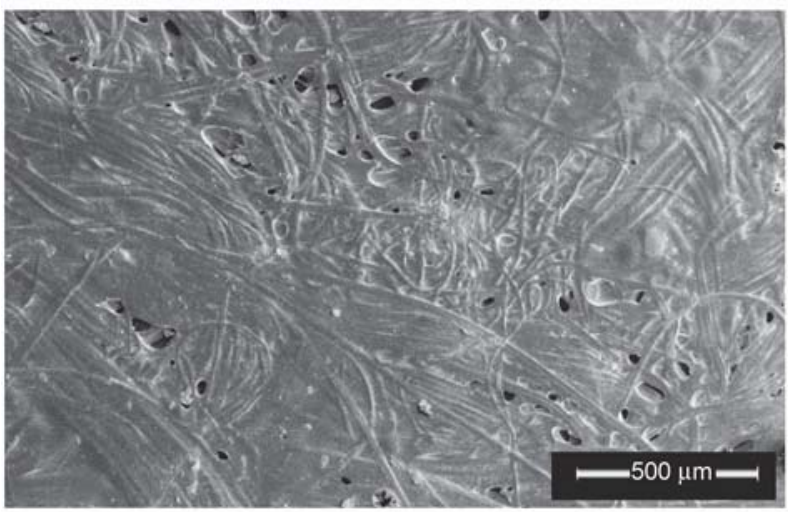

c)

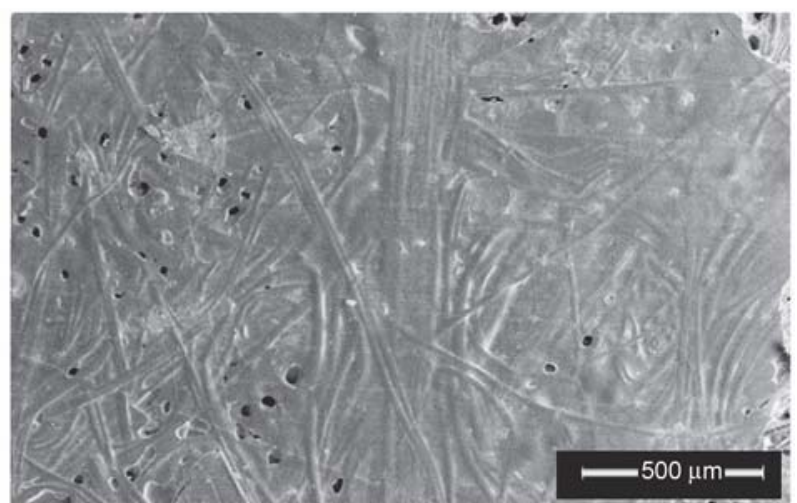

b)

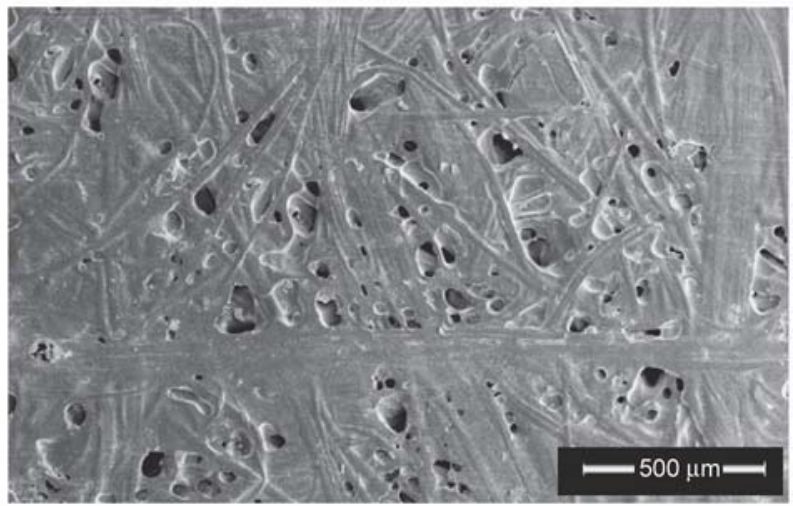

d)

Figure 7. SEM micrographs showing surface appearance of composites: (a) SS0, (b) SS10, (c) SS20, (d) SS30.

reinforced Acrodur biocomposites due to the evaporation of carboxylic acid during curing will results in the formation of void in the samples.

Figure 7 shows the surface appearance of NFA composites at varied SS loadings. Upon absence of SS, the surface was relatively smooth and displayed some evidence of porosity; indicating the capability and the efficiency of Acrodur resin to impregnate into the natural fibre mat. However, increment in SS loading compromised the quality of impregnation and the presence of voids became more apparent.

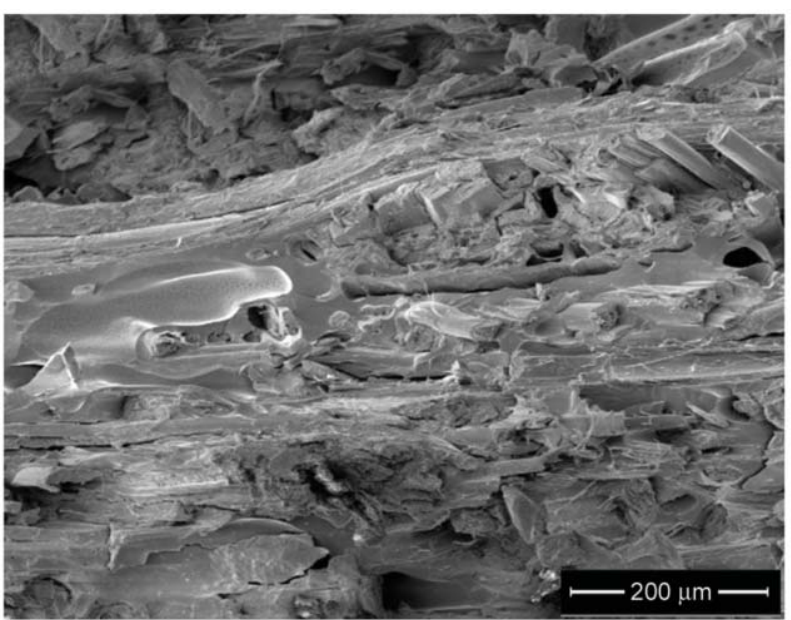

a)
The presence of voids was also observed from the SEM images of fractured surface of NFA composites (see Figure 8). In fact, more voids were noted in the samples at higher SS loading. This observation did not only explain the reduction in densities of the NFA composites, but also the deterioration of flexural properties of the NFA composite with increased SS loading. This supports our earlier claim that SS could probably interfere in the curing process of the polyester, while evaporation of alcohols and acids may be due to the high temperature during the moulding process.

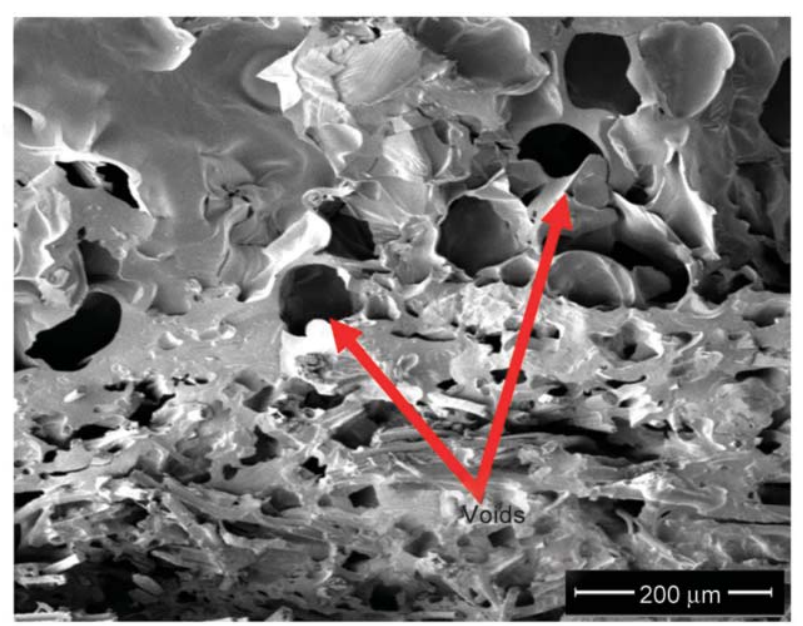

b)

Figure 8. SEM micrographs of the fracture surface of composites: (a) SS0, (b) SS30. 


\subsection{Flammability test}

The effects of SS loading on UL-94 ratings and LOI values of NFA composites are presented in Table 6 . The addition of SS from 10 to $30 \mathrm{wt} \%$ improved the fire rating from $\mathrm{V}-1$ to $\mathrm{V}-0$. The burning time of the composites was reduced from 154 to $35 \mathrm{~s}$. Besides, no dripping was observed during the tests. A similar trend was noted for LOI as well. The values increased with increment in SS loading. Based on LOI classification [34], materials with LOI values above $26-28 \%$ could be classified as self-extinguishing. UL-94 and LOI results demonstrated that the SS was indeed effective in improving the flame-retardancy feature in NFA composites. The flame-retardant property signified that the generated charring of the polysilicate deposited on the composite served as heat barrier and hindered further combustion of the NFA composites.

As mentioned earlier in Section 3.2, the introduction of SS into the Acrodur ${ }^{\mathbb{B}}$ resin during the fabrication of composites contributed to the formation of polysilicates. The presence of SS had an effect on higher char formation, as observed in Table 4 of Section 3.3. Upon exposure to heat, the polysilicate formed a protective layer of carbonaceous foamy glassy layer and insulated the surface on the composite (see Figure 9). This acted as heat and oxygen barrier, which prevented further combustion of the composite by reducing the diffusion of oxygen and heat transfer from polymer to flame [35].

\subsection{Acoustic properties}

Figure 10 illustrates the sound absorption curves for non-woven flax fibre and its NFA composites with varying SS loading. The non-woven flax fibre mat displayed a typical broad sound absorption curve for the natural fibres. Yang and Li [36] investigated several types of natural fibres and discovered similar noise absorption pattern to that noted in this present study. This indicated the excellent sound absorption characteristic of non-woven mats, hence explaining their popularity as sound absorption materials in automotive. Good sound absorption property of nonwoven mat could be attributed to the microstructures of natural fibres, which exerted better sound absorption performance of natural fibre reinforced composites. Natural fibres are porous fibre materials that contain many connected open air cavities known as hollow lumen structures, as shown by SEM images portrayed in Figure 11a. The sound wave could propagate by vibration through the air spaces and inside the lumen, in which the friction effect between cell wall and air flow could transform sound energy into heat.

Table 6. Classification of flammability of NFA composites with different SS loading according to UL-94 test.

\begin{tabular}{|l|c|c|c|c|c|}
\hline \multicolumn{1}{|c|}{ Composites } & Classification & Dripping observed & $\begin{array}{c}\text { Glowing or flaming } \\
\text { combustion to holding clamp }\end{array}$ & $\begin{array}{c}\text { Total flaming combustion } \\
\text { for all 5 specimens } \\
\text { [s] }\end{array}$ & $\begin{array}{c}\text { LOI } \\
\text { [\%] }\end{array}$ \\
\hline SS0 & V-1 & No & No & $154 \pm 6$ & 24.33 \\
\hline SS10 & V-1 & No & No & $102 \pm 7$ & 33.25 \\
\hline SS20 & V-0 & No & No & $43 \pm 5$ & 37.07 \\
\hline SS30 & V-0 & No & No & $35 \pm 6$ & 40.15 \\
\hline
\end{tabular}

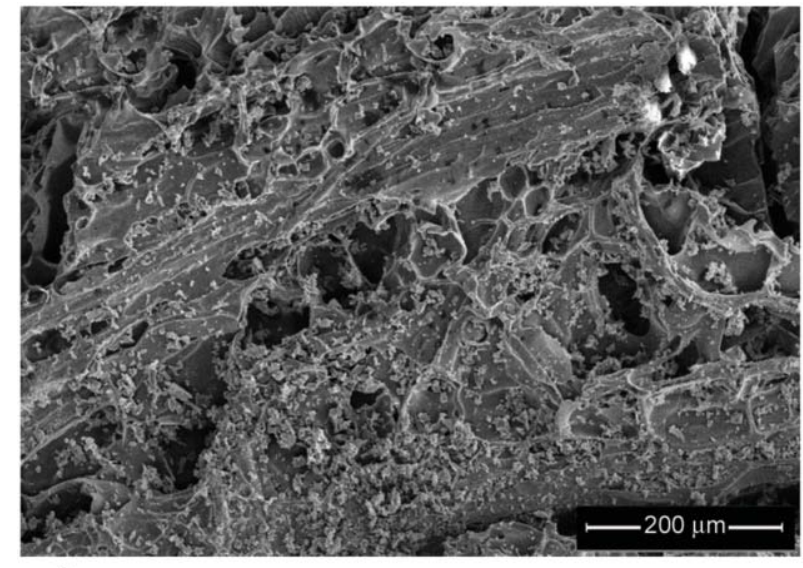

a)

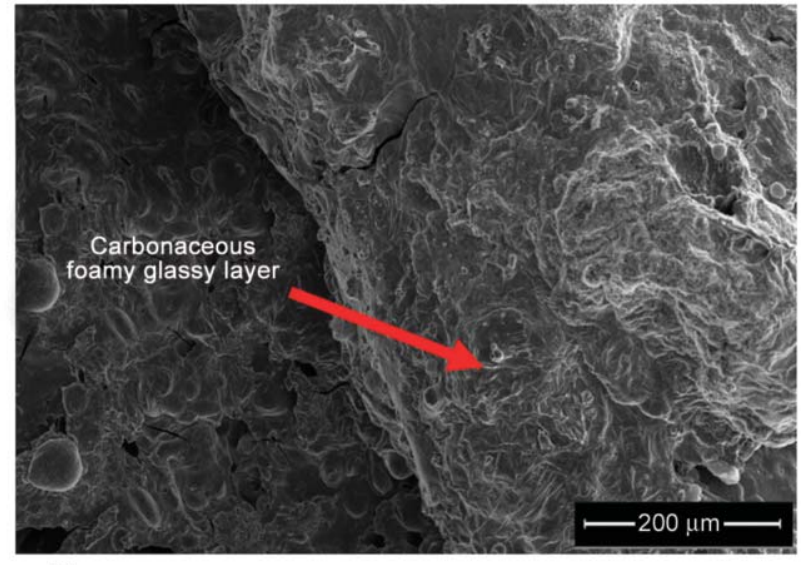

b)

Figure 9. SEM micrographs of the surface of composites after flammability test: (a) SS0, (b) SS30. 


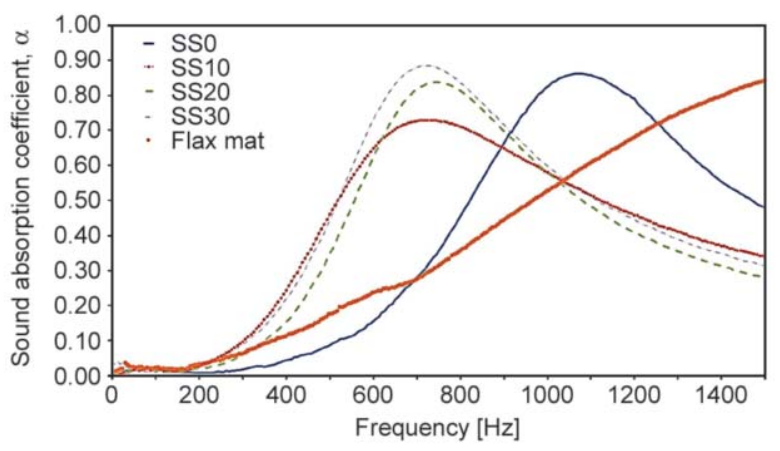

Figure 10. Sound absorption coefficient of non-woven flax and NFA composites.

In the case of NFA composites, all the samples exhibited similar pattern of sound absorption throughout the frequency range studied. The absorption curves were relatively narrower and reached the peak values within frequencies ranging between 750 and $1000 \mathrm{~Hz}$. The presence of SS did not seem to produce any adverse effect on the capability of NFA composites to absorb sound in the stated frequency range. SS10, SS20, and SS30 displayed slightly higher sound absorption coefficient $(\alpha)$ at lower frequency range of $50-800 \mathrm{~Hz}$, in comparison to SS0. At $700 \mathrm{~Hz}, \alpha$ values of $0.73,0.81$, and 0.87 were recorded for SS10, SS20, and SS30, respectively. This could be attributed to the rougher surface, irregular structure on the composite surface (see Figure 7), and significant increase in void content (see Table 5) of the NFA composites. Chen et al. [37] reported higher void content and rougher structure that led to higher friction and heat energy, thus strengthening the effect of sound absorption. However, at $1000 \mathrm{~Hz}$ frequency, $\alpha$ reduced significantly from 0.85 to 0.50 , which contributed to $41 \%$ reduction.

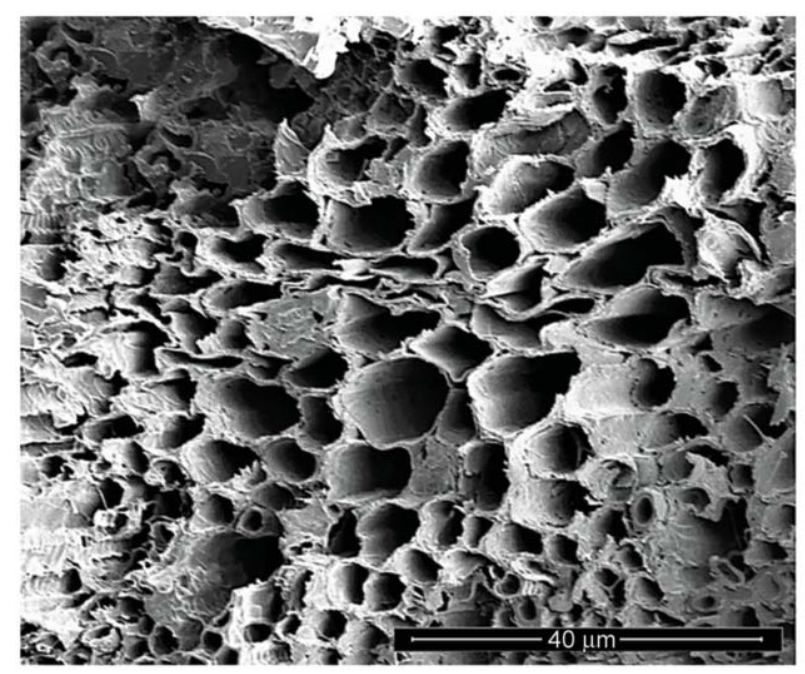

a)

Figure 11. SEM images showing the existence of hollow: (a) flax mat, (b) SS20.
On the contrary, the sound absorption coefficient of NFA composite in the absence of SS, i.e. SS0, still increased as it adhered to the trend of non-woven flax fibre mat. The composite registered peak $\alpha$ value of 0.85 at $1100 \mathrm{~Hz}$ frequency. Next, the $\alpha$ values began to decline gradually following the same trend to those displayed by NFA composites at varied SS loadings. The relatively poor sound absorption characteristics of NFA composites at frequencies exceeding 1500, when compared to that of non-woven flax fibre mat, can be attributed to the fact that in the composites, not all lumen remained unoccupied as revealed by SEM image shown in Figure 11. During the impregnation and the moulding processes, the low viscosity of Acrodur resin managed to flow between the fibre structures and occupied the hollow lumen that could have reduced sound absorption coefficient, especially within the high frequency range. However, as pointed earlier, reduction in the quantity of hollow lumen is believed to be compensated by the presence of high porosity in NFA composites, as indicated in Table 5, which could also be a major contributor of sound energy absorption. Seddeq [38], asserted that a large number of voids allowed sound dissipation as sound waves are more likely to penetrate the voids, pass through them, and get dampened.

\section{Conclusions}

Incorporation of SS into NFA composites has produced products with good mechanical, flammability, and acoustic properties. SS contributed positively towards enhancing the flame retardancy feature of NFA composites. The flame extinguished by itself during

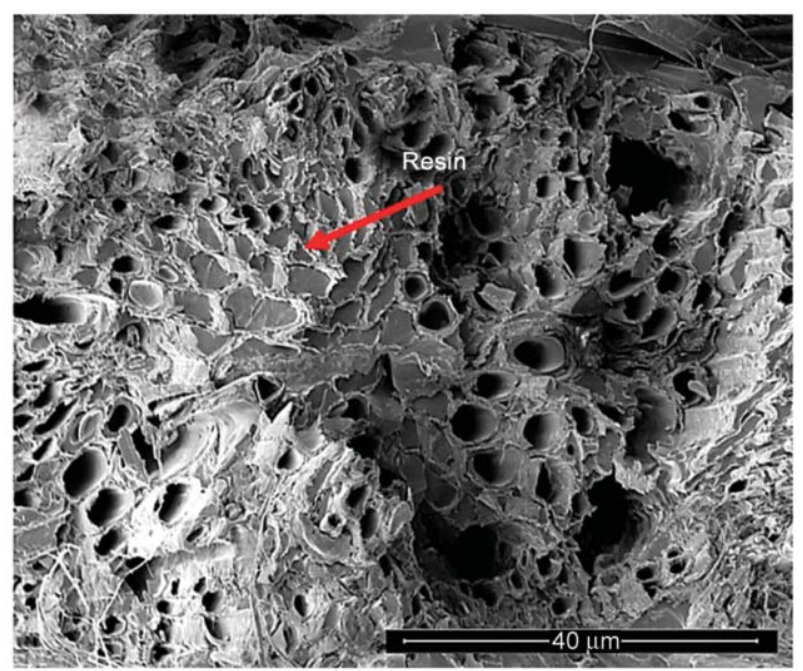


the fire testing, hence giving an excellent UL94 classification of V-0. Enhancement in flame-retardant efficiency of the composites that contained SS was quantitatively verified by the increasing LOI values of the composites. The presence of voids, as a consequence of the cross-linking process of Acrodur, did not produce any detrimental effect on the mechanical performance of the composites. On the contrary, it contributed positively towards improving the sound absorption capability of the NFA composites. The addition of SS up to $20 \mathrm{wt} \%$ had nil impact on both flexural strength and modulus, wherein the NFA composites displayed excellent sound absorption properties up to $1000 \mathrm{~Hz}$ frequency, which is considered as an essential requirement to serve as interior components within the automotive arena.

\section{Acknowledgements}

The authors would like to acknowledge the financial support given by Universiti Sains Malaysia and the Ministry of Education by providing RUC Grant (Grant no:no.1001/PBAHAN/814134) and LRGS Grant (Grant no: 1001/PKT/ 8640012), respectively.

\section{References}

[1] Ratna Prasad A. V., Mohana Rao K.: Mechanical properties of natural fibre reinforced polyester composites: Jowar, sisal and bamboo. Materials and Design, 32, 4658-4663 (2011). https://doi.org/10.1016/j.matdes.2011.03.015

[2] Rasyid M. F. A., Salim M. S., Akil H. M., Ishak Z. A. M.: Optimization of processing conditions via response surface methodology (RSM) of nonwoven flax fibre reinforced Acrodur biocomposites. Procedia Chemistry, 19, 469-476 (2016). https://doi.org/10.1016/j.proche.2016.03.040

[3] Phiri G., Khoathane M. C., Sadiku E. R.: Effect of fibre loading on mechanical and thermal properties of sisal and kenaf fibre-reinforced injection moulded composites. Journal of Reinforced Plastics and Composites, 33, 283-293 (2014).

https://doi.org/10.1177/0731684413511548

[4] Akampumuza O., Wambua P. M., Ahmed A., Li W., Qin $\mathrm{X}-\mathrm{H}$.: Review of the applications of biocomposites in the automotive industry. Polymer Composites, 38, 2553-2569 (2017). https://doi.org/10.1002/pc.23847

[5] Zhu J., Zhu H., Njuguna J., Abhyankar H.: Recent development of flax fibres and their reinforced composites based on different polymeric matrices. Materials, 6, 5171-5198 (2013).

https://doi.org/10.3390/ma6115171
[6] Kabir M. M., Wang H., Lau K. T., Cardona F.: Chemical treatments on plant-based natural fibre reinforced polymer composites: An overview. Composites Part B: Engineering, 43, 2883-2892 (2012). https://doi.org/10.1016/j.compositesb.2012.04.053

[7] Dicker M. P. M., Duckworth P. F., Baker A. B., Francois G., Hazzard M. K., Weaver P. M.: Green composites: A review of material attributes and complementary applications. Composites Part A: Applied Science and Manufacturing, 56, 280-289 (2014). https://doi.org/10.1016/j.compositesa.2013.10.014

[8] Furtado S. C., Araújo A. L., Silva A., Alves C., Ribeiro A. M. R. A.: Natural fibre-reinforced composite parts for automotive applications. International Journal of Automotive Composites, 1, 18-38 (2014). https://doi.org/10.1504/IJAUTOC.2014.064112

[9] Cordeiro N., Gouveia C., John M. J.: Investigation of surface properties of physico-chemically modified natural fibres using inverse gas chromatography. Industrial Crops and Products, 33, 108-115 (2011). https://doi.org/10.1016/j.indcrop.2010.09.008

[10] Yan L., Chouw N., Yuan X.: Improving the mechanical properties of natural fibre fabric reinforced epoxy composites by alkali treatment. Journal of Reinforced Plastics and Composites, 31, 425-437 (2012). https://doi.org/10.1177/0731684412439494

[11] Peng X., Zhong L., Ren J., Sun R.: Laccase and alkali treatments of cellulose fibre: Surface lignin and its influences on fibre surface properties and interfacial behaviour of sisal fibre/phenolic resin composites. Composites Part A: Applied Science and Manufacturing, 41, 1848-1856 (2010). https://doi.org/10.1016/j.compositesa.2010.09.004

[12] Bessadok A., Marais S., Gouanvé F., Colasse L., Zimmerlin I., Roudesli S., Métayer M.: Effect of chemical treatments of Alfa (Stipa tenacissima) fibres on watersorption properties. Composites Science and Technology, 67, 685-697 (2007). https://doi.org/10.1016/j.compscitech.2006.04.013

[13] Le Troedec M., Sedan D., Peyratout C., Bonnet J. P., Smith A., Guinebretiere R., Gloaguen V., Krausz P.: Influence of various chemical treatments on the composition and structure of hemp fibres. Composites Part A: Applied Science and Manufacturing, 39, 514-522 (2008). https://doi.org/10.1016/j.compositesa.2007.12.001

[14] Fatima S., Mohanty A. R.: Acoustical and fire-retardant properties of jute composite materials. Applied Acoustics, 72, 108-114 (2011). https://doi.org/10.1016/j.apacoust.2010.10.005

[15] Chapple S., Anandjiwala R.: Flammability of natural fiber-reinforced composites and strategies for fire retardancy: A review. Journal of Thermoplastic Composite Materials, 23, 871-893 (2010). https://doi.org/10.1177/0892705709356338 
[16] Umemura T., Arao Y., Nakamura S., Tomita Y., Tanaka T.: Synergy effects of wood flour and fire retardants in flammability of wood-plastic composites. Energy Procedia, 56, 48-56 (2014).

https://doi.org/10.1016/j.egypro.2014.07.130

[17] Battegazzore D., Alongi J., Duraccio D., Frache A.: Reuse and valorisation of hemp fibres and rice husk particles for fire resistant fibreboards and particleboards. Journal of Polymers and the Environment, 26, 3731-3744 (2018).

https://doi.org/10.1007/s10924-018-1250-3

[18] Battegazzore D., Alongi J., Frache A., Wågberg L., Carosio F.: Layer by layer-functionalized rice husk particles: A novel and sustainable solution for particleboard production. Materials Today Communications, 13, 92 101 (2017).

https://doi.org/10.1016/j.mtcomm.2017.09.006

[19] Islam M. S., Miao M.: Optimising processing conditions of flax fabric reinforced Acrodur biocomposites. Journal of Composite Materials, 48, 3281-3292 (2013). https://doi.org/10.1177/0021998313508995

[20] Liu Y-L., Hsiue G-H., Chiu Y-S., Jeng R-J., Perng L-H.: Phosphorus-containing epoxy for flame retardant. I. Synthesis, thermal, and flame-retardant properties. Journal of Applied Polymer Science, 61, 613-621 (1996). https://doi.org/10.1002/(SICI)10974628(19960725)61:4<613::AID-APP5>3.0.CO;2-O

[21] Guo C., Zhou L., Lv J.: Effects of expandable graphite and modified ammonium polyphosphate on the flameretardant and mechanical properties of wood flourpolypropylene composites. Polymers and Polymer Composites, 21, 449-456 (2013). https://doi.org/10.1177/096739111302100706

[22] Jeencham R., Suppakarn N., Jarukumjorn K.: Effect of flame retardants on flame retardant, mechanical, and thermal properties of sisal fiber/polypropylene composites. Composites Part B: Engineering, 56, 249-253 (2014). https://doi.org/10.1016/j.compositesb.2013.08.012

[23] Kicko-Walczak E.: Evaluation of the fire-retardant properties of new modifiers in unsaturated polyester resins using the cone calorimetric method. Macromolecular Symposia, 202, 221-233 (2003). https://doi.org/10.1002/masy.200351219

[24] Jiang X-M., Rui Y-N., Chen G-Q.: Improved properties of cotton by atmospheric pressure plasma polymerization deposition of sericin. Journal of Vinyl and Additive Technology, 21, 129-133 (2009).

https://doi.org/10.1002/vnl.20185

[25] Sahoo P. K., Samal R., Swain S. K., Rana P. K.: Synthesis of poly(butyl acrylate)/sodium silicate nanocomposite fire retardant. European Polymer Journal, 44, 3522-3528 (2008).

https://doi.org/10.1016/j.eurpolymj.2008.08.033

[26] Cheng J-J., Zhou F-B.: Flame-retardant properties of sodium silicate/polyisocyanate organic-inorganic hybrid material. Journal of Thermal Analysis and Calorimetry, 125, 913-918 (2016).

https://doi.org/10.1007/s10973-016-5454-2
[27] Medina L. A., Schledjewski R.: Water glass as hydrophobic additive for natural fibre reinforced composites. Journal of Nanostructure Polymers and Nanocomposites, 5, 107-114 (2009).

[28] Lalor N., Priebsch H. H.: The prediction of low- and mid-frequency internal road vehicle noise: A literature survey. Proceedings of the Institution of Mechanical Engineers Part D: Journal of Automobile Engineering, 221, 245-269 (2007) https://doi.org/10.1243/09544070JAUTO199

[29] Khalfallah M., Abbès B., Abbès F., Guo Y. Q. Q., Marcel V., Duval A., Vanfleteren F., Rousseau F.: Innovative flax tapes reinforced Acrodur biocomposites: A new alternative for automotive applications. Materials and Design, 64, 116-126 (2014).

https://doi.org/10.1016/j.matdes.2014.07.029

[30] Akpan E. I., Wetzel B., Friedrich K.: Processing and properties of short wood fiber/acrylate resin composites. Polymer Composites, 40, 91-98 (2019).

https://doi.org/10.1002/pc.24604

[31] Cheng J-J., Shi B. B., Zhou F. B., Chen X. Y.: Effects of inorganic fillers on the flame-retardant and mechanical properties of rigid polyurethane foams. Journal of Applied Polymer Science, 131, 1-9 (2014).

https://doi.org/10.1002/app.40253

[32] Kashiwagi T., Du F., Douglas J. F., Winey K. I., Harris R. H., Shields J. R.: Nanoparticle networks reduce the flammability of polymer nanocomposites. Nature Materials, 4, 928-933 (2005).

https://doi.org/10.1038/nmat1502

[33] Vaia R. A., Price G., Ruth P. N., Nguyen H. T., Lichtenhan J.: Polymer/layered silicate nanocomposites as high performance ablative materials. Applied Clay Science, 15, 67-92 (1999).

https://doi.org/10.1016/S0169-1317(99)00013-7

[34] Schartel B., Braun U., Schwarz U., Reinemann S.: Fire retardancy of polypropylene/flax blends. Polymer, 44, 6241-6250 (2003). https://doi.org/10.1016/S0032-3861(03)00692-X

[35] Kiliaris P., Papaspyrides C. D.: Polymer/layered silicate (clay) nanocomposites: An overview of flame retardancy. Progress in Polymer Science, 35, 902-958 (2010). https://doi.org/10.1016/j.progpolymsci.2010.03.001

[36] Yang W., Li Y.: Sound absorption performance of natural fibers and their composites. Science China Technological Sciences, 55, 2278-2283 (2012). https://doi.org/10.1007/s11431-012-4943-1

[37] Chen D., Li J., Ren J.: Study on sound absorption property of ramie fiber reinforced poly(L-lactic acid) composites: Morphology and properties. Composites Part A: Applied Science and Manufacturing, 41, 1012-1018 (2010). https://doi.org/10.1016/j.compositesa.2010.04.007

[38] Seddeq H. S.: Factors influencing acoustic performance of sound absorptive materials. Australian Journal of Basic and Applied Sciences, 3, 4610-4617 (2009). 